\title{
Changing behavior using control theory
}

\section{Document Version}

Accepted author manuscript

Link to publication record in Manchester Research Explorer

\section{Citation for published version (APA):}

Mansell, W. (2020). Changing behavior using control theory. In M. S. Hagger, L. D. Cameron, K. Hamilton, N. Hankonen, \& T. Lintunen (Eds.), The handbook of behavior change (pp. 120-135). Cambridge University Press.

\section{Published in:}

The handbook of behavior change

\section{Citing this paper}

Please note that where the full-text provided on Manchester Research Explorer is the Author Accepted Manuscript or Proof version this may differ from the final Published version. If citing, it is advised that you check and use the publisher's definitive version.

\section{General rights}

Copyright and moral rights for the publications made accessible in the Research Explorer are retained by the authors and/or other copyright owners and it is a condition of accessing publications that users recognise and abide by the legal requirements associated with these rights.

\section{Takedown policy}

If you believe that this document breaches copyright please refer to the University of Manchester's Takedown Procedures [http://man.ac.uk/04Y6Bo] or contact uml.scholarlycommunications@manchester.ac.uk providing relevant details, so we can investigate your claim.

\section{OPEN ACCESS}




\title{
9 Changing Behavior Using Control Theory
}

\author{
Warren Mansell
}

\begin{abstract}
Practical Summary
Have you ever heard someone say that they do not feel in control of their life? People tend to feel stressed or distressed when they cannot control things they feel are important to them, like feelings, a sense of self, or adherence to personal values. Control theory states that control is fundamental to well-being and to the healthy functioning of any person, group of people, or organization. The theory also states that changing behavior allows people to counteract disturbances (obstacles, challenges) that can threaten their ability to stay in control of their lives. So behavior change is at the very heart of well-being, at every moment of the day. This chapter focuses on how practitioners can draw on control theory to assist in making sustained behavior change that is beneficial to their well-being, such as helping parents manage their infant's development, helping recovery from mental health problems, organizing education and discipline within schools, and managing organizations.
\end{abstract}

\subsection{Introduction}

The application of control theory in psychology has its basis in control engineering. It is also closely related to the field of cybernetics that emerged in the 1940s and 1950s. This chapter focuses on the form of control theory described by Powers (1973/2005, 2008). Powers's theory has provided the basis of an important strand of self-regulation theory within social and clinical psychology (Carver \& Scheier, 1982), as well as, more recently, informing psychotherapy, neuroscience, child development, education, sociology, and organizational psychology (for a historical view on Powers's work, see Sidebar 9.1). The theory, also known as perceptual control theory, has also provided an integrative framework for theories of behavior change to inform interventions for addiction (Webb, Sniehotta, \& Michie, 2010). The theory proposes that behavior changes continuously in order to control one's perception of aspects of the self and the environment. Control theory proposes that life requires "control" (Powers, 1973/2005), that well-being and mental health require control (Carey, 2006), and that good health also requires control (Carey, 2017). The purpose of this chapter is to review control theory and its evidence, to propose how it accounts for behavior change, and to describe examples of the interventions informed by the theory and evidence for their effectiveness. 
Sidebar 9.1 A history lesson: What happened to Powers's control theory?

William T. Powers (1926-2013) based his version of control theory on his knowledge of the artificial control systems he encountered as a medical physicist and engineer. He realized that even control systems machines control their inputs, not their outputs. Take the humble thermostat. It controls its perception of the current temperature, keeping it as close as possible to the value set by its human user. Control theory ideas had been applied to human behavior before, within the cybernetic movement (Ashby, 1952; Wiener, 1948), but Powers showed that these models made the "input blunder," assuming that control occurred on the output side of the model (Powers, 1978). Powers had hoped that his first papers, his well-received first book (Powers, 1973/2005), and his landmark Psychological Review article (Powers, 1978) would change the course of psychological research. He hoped that scientists of behavior would begin to develop tests of what perceived aspects of the self or the environment a person was controlling. Yet, even now, the predominant research methodology involves studying the linear relationship between stimuli, cognitive processes, and responses (Mansell \& Huddy, 2018).

\subsection{Overview of Control Theory and Evidence}

The basic "unit" of control theory is the negative feedback loop (see Figure 9.1). ${ }^{1}$ The loop is a functional subsystem - or a working model that can be used to simulate human (or animal) behavior and even to operate robotic systems (Vancouver, 2005; Young, 2017). These basic subsystems are organized in a branching hierarchy to model behavior in detail. In essence, people achieve long-term goals (e.g., to be healthy) by setting lower-level subgoals (e.g., to exercise), which in turn set subgoals at a lower level (e.g., to run), which, in turn, set subgoals (e.g., legs moving fast). These layers continue downward, at each layer specifying increasingly concrete, sensory inputs. Every level is being controlled simultaneously to flexibly achieve the long-term goals.

The purpose of the negative feedback loop is to control some perceived aspect of the self or the world. Consider a concrete real-world example walking on a tightrope. Some tightrope walkers report that they focus on an object ahead of them. The location of this object in their field of vision would be the controlled variable. The walker has an internally specified goal, standard, or reference value for the location of this object - at the center of their vision. The current state of the variable is compared continuously with the reference value using a comparator. This generates a discrepancy, or error, which is amplified by a gain value, to drive a change in behavior that acts against disturbances in the environment, to keep the variable at, or as close as possible to, the reference value. Disturbances come from wind and from the movements of the walker's own body and the rope. The actions of the walker are channeled through the environment to have their effects. The properties of the body and environment that allow this are called its feedback function. Because the loop is working continuously, the disturbances are continuously

\footnotetext{
1 The term "negative" feedback should not imply criticism or a negative emotional tone. It means that the actions of the system are subtracted from the disturbances in the environment in order to reduce error and meet a goal. In contrast, a "positive" feedback loop adds to the disturbance to increase error, which makes it inherently unstable and often regulated, in turn, by a negative feedback loop to restore control.
} 


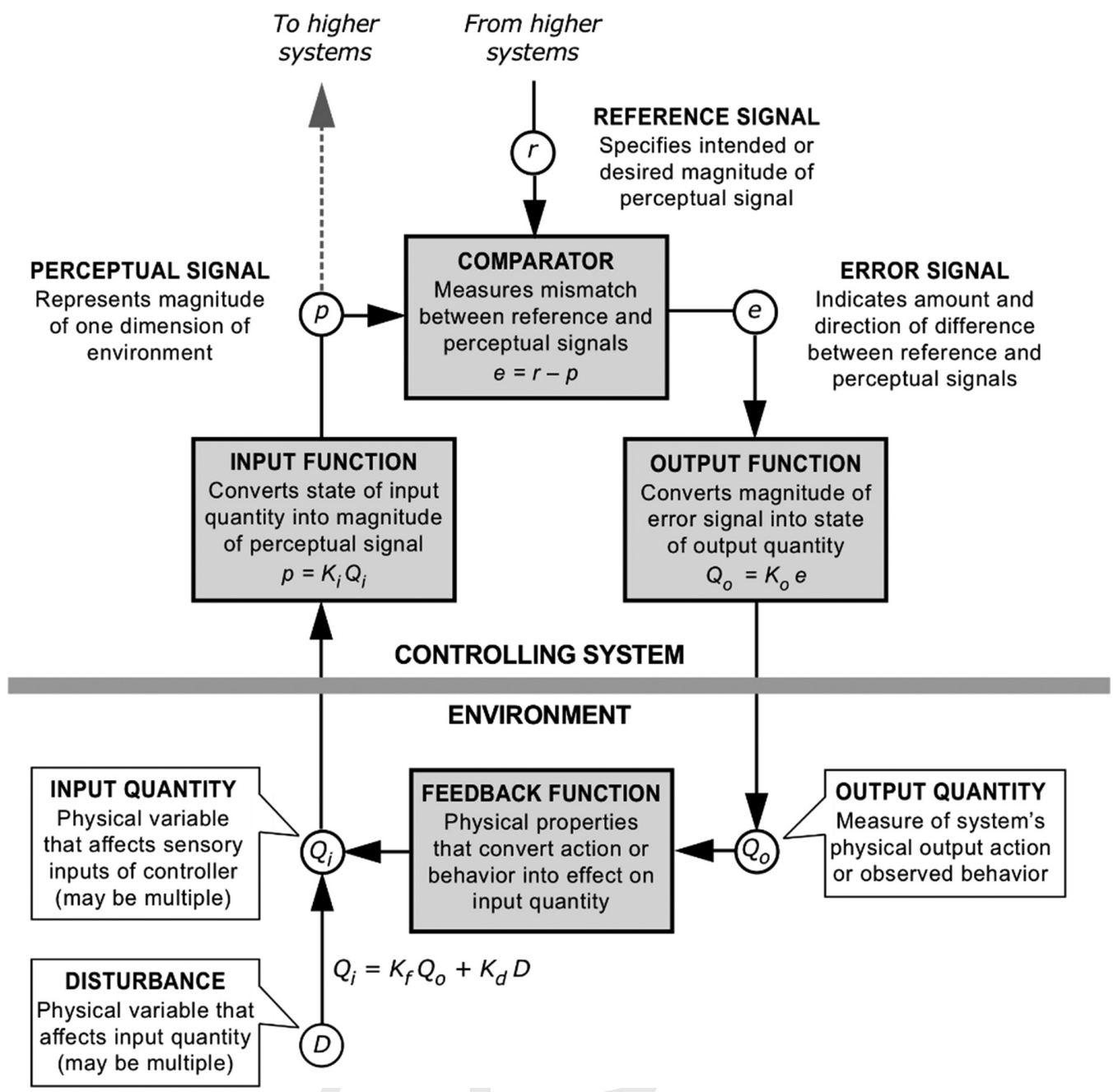

Figure 9.1 The feedback control unit Note. Adapted with permission from Forssell, D. (2008). Management and Leadership: Insight for Effective Practice. Hayward, CA: Living Control Systems Publications from an original diagram by William T. Powers.

counteracted as soon as they occur, maintaining stability. A clear implication of this model, so far, is that people control their input (perception) by varying their outputs (actions) in an ongoing manner. This occurs automatically and does not require conscious awareness - in fact, as described in Section 9.3.5, awareness is often focused only on a subset of the perceptions being controlled.

Powers proposed that this unit of control is fundamental to behavior. It applies at more abstract levels - such as trying to "make a good impression" - and even to behaviors that appear to be "triggered" as fixed, planned actions (see Figure 9.1). For example, the deliberate behavior of "being a good listener" requires that a person can perceive how much they are listening (the perceptual signal) and compare this to a reference value of how good at listening they want to be (reference value and comparator) to generate a discrepancy or error signal and engage in any actions (output quantities) 
within the environment (feedback function) necessary to act against any disturbances (e.g., to ask the person to speak louder when there is loud background noise) to keep the perceptual signal close to the reference value. Often when it appears that a "stimulus" has triggered a response, this happens because the disturbance is occurring in a sudden rather than smooth manner. For example, the classic "startle" response to a loud noise occurs because the startled person has a reference value for their desired loudness level of surrounding noise. The sudden onset of a loud noise disturbs this variable very quickly, creating large error and therefore a large response. However, as the onset is lengthened in time (e.g., when the volume increases steadily), the momentary error level is lower, giving more time for other varied actions to be utilized (e.g., saying "turn that noise down!").

A series of reviews have summarized the evidence for the control theory tenet that behavior is the control of perceptual input (Mansell \& Huddy, 2018; Marken \& Mansell, 2013). Around twenty studies have used evidence from manual tracking in which the user moves a computer mouse or joystick to control some aspect of the visual display despite disturbances to this variable that are provided by the computer. The studies show that control theory can be used to infer what variable the participant is controlling, such as the position of a moving cursor (Powers, 1978). In each of these studies, behavior is changing continuously, yet a perceptual variable is being kept at a desired value. Furthermore, when comparative tests have been carried out, the perceptual control theory models outperform alternative models in their match with behavioral data. These include the domains of tracking performance (Bourbon \& Powers, 1999), robotics (Rabinovich \& Jennings, 2010), experimental psychology (Marken, 2013), and organizational psychology (Vancouver \& Scherbaum, 2008). Controversially, a series of studies have challenged the assumption that increased self-efficacy, a belief in one's own mastery of a skill (see Chapters 3 and 32, this volume), improves performance (e.g., Halper, Vancouver, \& Bayes, 2018; Vancouver et al., 2014). Rather, based on a control theory model, these studies show that reductions in self-efficacy can be associated with improvements in performance because individuals use the discrepancy between their desired and actual performance to increase their effort and improve performance.

Within the clinical realm, a recent series of studies presented participants with an image of a spider within a virtual corridor that moved toward and away from the participant. Thus, at any moment, the participant's actions needed to vary to control the perceived distance from the spider. The spider-fearful participants kept their distance at a value greater than people with low levels of spider fear (Oliver \& Mansell, 2018), even when they were required to learn new actions on each trial of the task. Taken together, the "control of input" model of behavior appears well supported by empirical evidence, despite the fact that most studies of behavior assume a "control of output" model, namely that behavior is controlled through planning, learning, or reinforcement.

The inherent nature of behavior as dynamically changing has major implications for any model of "behavior change." Powers (1992) suggests that "We think that our lives are full of repetitive and familiar actions, but to say that we 'do the same thing' every day is only a way of speaking ... Controlling means producing repeatable consequences by variable actions" (p. 5; emphasis added). Yet the converse conclusion, that actions can be determined precisely as the way to counteract a current disturbance-given our adherence to a specific goal - is also true. Control theory entails a paradoxical relationship between pursuing a goal and the degree of control one has over one's actions in doing so. People potentially surrender control of their actions to external forces in order to achieve a goal. The often complex concrete actions that individuals use to achieve a goal need to change dynamically in order to achieve that goal. For example, for a smoker to be able to 
draw cigarette smoke into his lungs, he needs to find a shop that sells cigarettes, ask for a packet, hand over the correct money, take the packet, open it, take a cigarette out, light it, put it to his lips, and inhale. These behaviors vary as necessary depending on the location of the shop, the price of the cigarettes, the size of the packet, the location of the lighter, and so on. So when a researcher says they are attempting to make smokers "change their behavior," this cannot be an accurate description of the aim. A more successful aim would be to help people to not to want to perceive inhaling cigarette smoke and its consequential effects on the mind and body (see Figure 9.2). However, by explaining the aim in this way, it seems like a goal to attain "mind control," which is maybe why it is avoided, because it both feels unethical and seems

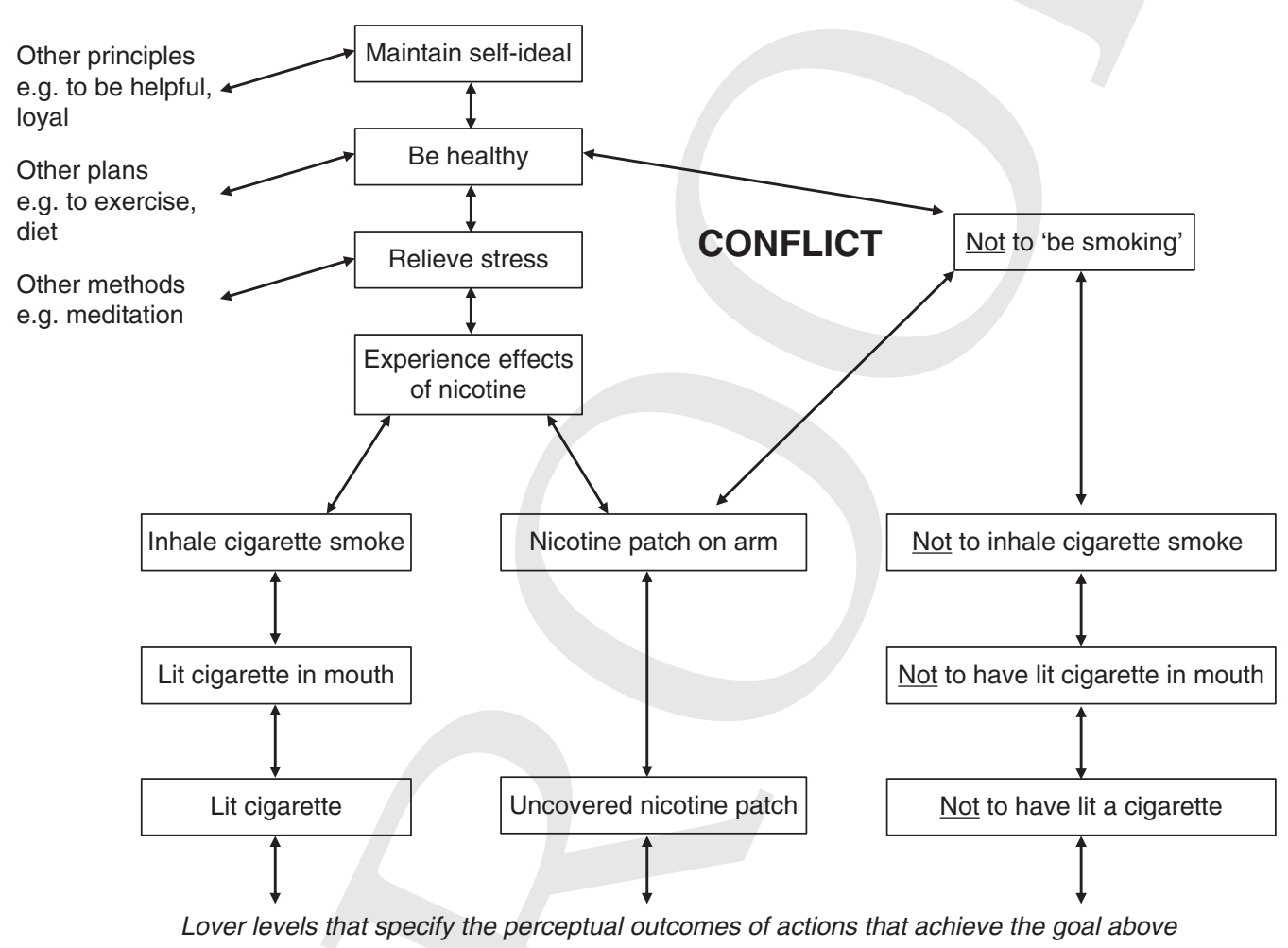

Figure 9.2 An example of a control hierarchy for smoking behavior

Note. This figure illustrates the multiple levels that may be involved in smoking behavior. Starting from the most abstract level - the self-ideal, which approximates to the system concept (Powers, 1973), each level down specifies a branching array of increasingly more concrete perceptual experiences that are controlled in order to maintain the highest level of perception. At each level, only one or two branches are shown but examples of other, parallel perceptual goals are described at the left of the figure. This diagram illustrates the goal conflict involved within one hypothetical person who regards smoking as a way to reduce stress and stay healthy because they also recognize that stopping smoking will improve their health. The diagram shows two alternative behaviors stopping smoking or using nicotine patches. The latter alternative may provide a way to relieve stress while ceasing smoking. 
impossible. It is not impossible to the degree that the manipulated person adheres to a specific goal (e.g., to be liked by the manipulator), but it would not be a helpful way to organize a successful intervention that ultimately improved health and well-being. Instead the environmental conditions need to be created that help people make the intrinsic changes that work for them.

\subsection{Mechanisms of Behavior Change}

In addition to the workings of a control loop, a range of other principles form the architecture of control theory and allow the implications for behavior change to be elaborated. These principles are hierarchical levels, conflict, and reorganization. In the next section, these principles are introduced within a control theory account of the possible reasons for any behavior change. They are summarized as a table in Appendix 9.1 (supplemental materials).

\subsubsection{Unlearned Mechanisms}

The wider implication of the control theory model for behavior change is that behavior is changing most of the time to control perceptual input, and often these changes are not signs of any new learning but just the normal operation of a control system in the face of disturbances or changing feedback functions (see Figure 9.1). These changes typically happen automatically and unconsciously. One could call these unlearned reasons for behavior change, and they include incidents in which the person is trying to control their inputs but is not able to sufficiently. This happens, for example, to the person who has their house flooded and can no longer use all of the feedback functions built into their home to keep them safe, warm, and in touch with other people. Changes that undermine control can be subtle too. Consider, for example, the wellknown "nudge" effects (Thaler \& Sunstein,
2008), such as when a supermarket places confectionery at the checkout, making it harder for shoppers to avoid buying unhealthy food choices (see Chapter 14, this volume). Even though the immediate changes in behavior that emerge from altering disturbances and feedback functions are not learned, they can still be important because they either help or hinder individuals to achieve their goals. Yet, if the goal is important to the individual, they will adapt to meet it, as described in the next section.

\subsubsection{Learned Mechanisms}

So when does a change in behavior actually indicate a more enduring form of learning? There are many mechanisms available but none of them can be targeted directly by psychological interventions because they change within the nervous system of the individual. Yet they will change spontaneously through learning as one attempts to optimize one's control during development and as the individual accesses new, and changing, environments.

The elements of the negative feedback loop indicate where learning can occur and they provide some examples of learned reasons for behavior change (see Figure 9.1). First, the perceptual function that allows the person to perceive the state of the controlled variable can change. For example, an experienced firefighter improves in her ability to sense the location of a fire, and a man who regularly experiences panic attacks gets more accurate at detecting his own heart rate. Second, the reference value can change. For example, a woman with anorexia may set lower and lower values for the feeling of fullness she is willing to tolerate. According to control theory, the principal purpose of memory is to store reference values. For example, a child stores the memory of the sights, sounds, and smells of her mother and father in order to get close to them when feeling hungry or unsafe. Third, the gain can change. This is often reflected in the amount of 
effort a person goes to in order to meet their standard. For example, a person addicted to heroin may go to huge lengths to obtain the drug. Finally, the output function can change; people can learn new means to achieve their goals, such as the gambler who finds new ways to get money to afford the next session at the casino. This last element sounds like a new behavior has been learned, but this is not exactly the case; outputs are also control perceptions. Within control theory, the outputs of a control unit specify the reference values for another control unit - the subgoal at the next level down in the hierarchy; the outputs do not specify actual muscle movements.

\subsubsection{Conflict}

The third indirect reason for behavior change that emerges from control theory is where the individual has lost control due to the effects of conflict. Conflict occurs when two or more control systems attempt to control the same variable at different reference values. It can occur between, or within, one or more individuals or groups. For example, international group conflict often occurs over disputed territory - the same variable, that is, the area of land - that is subject to two opposing standards: to be owned by country A versus to be owned by country B. An example of conflict between individuals is the sixteen-yearold girl who wants to go out with her friends but her mother wants her to stay at home. The same teenage girl may have internal conflict - whether to do what her mother says versus to disobey her. Behavior during conflict can take unusual forms. It can oscillate back and forth as both sides attempt to keep control. When this occurs within an individual, it appears as indecision, uncertainty, and confusion. Conflict can also entail one side "getting its way" while the other side maintains its contradictory standard and yet does not have the resources to win. In this context, a change in situation can "tip the balance" and allow the suppressed goal to flourish. One example of this is how the suppression of child abuse experiences can be maintained until the victim feels strong and supported enough to speak out and seek justice, with the \#MeToo movement a recent example. One further complex side effect of conflict is that two goals in conflict can increase their gain so much that the person overcompensates and their own attempts to counteract disturbances create more disturbances than they can counteract, oscillating the system out of control. It is feasible that such a process occurs in acute episodes of stress, panic, mania, and psychosis. Analogues of these features of conflict have been demonstrated using computer simulations based on control theory (Carey, 2008; McClelland, 2004). A more recent review found that goal conflict is associated with reduced wellbeing and mental health, and control theory has been used to integrate a range of well-known theoretical accounts of its effects (Kelly, Mansell, \& Wood, 2015).

\subsubsection{Reorganization}

The fourth indirect reason for behavior change relates to what occurs when a person attempts to regain control through a process known as reorganization. This is a trial-and-error process through which the elements of a control system (e.g., functions, gains, etc.) change in order to help regain control. As a person loses control of what matters to them, and error builds up, this ramps up the rate of random changes in the control system itself through new neural connections, resulting in, for example, new ways of perceiving (perceptual functions) and new ways of acting (output functions). Thus, apparently random, or unhelpful, behaviors can sometimes be observed in people who are attempting to try to regain control. The process of reorganization has been examined in computer simulations (Powers, 2008). Further studies have inferred that the process of reorganization is occurring when a period 
of poor performance precedes a sudden "step change" in ability during skill acquisition in infants (Sadurní, Burriel, \& Plooij, 2010) and in experimental tasks (Robertson \& Glines, 1985).

\subsubsection{Awareness}

The fifth and final indirect reason for observing behavior change is during changes in the focus and duration of awareness. Because conflict is the most pernicious factor that undermines control and cooperation between individuals, it is vital that human beings have a way to resolve it. Powers proposed that reorganization needs to be directed to the control system that is superordinate to the conflicting goals in order for the conflict to be resolved by trial-and-error changes in the parameters of that system. Thus, at any one point in time, the spotlight of awareness is directed to only a tiny subset of the control systems within an individual, and it occurs during the imagination mode, a specific configuration of control systems that permits mental simulation (Powers, Clark, \& McFarland, 1960). As a person's awareness shifts, this is likely to be accompanied by changes in behavior - for example, focusing on controlling visual imagery of one's goals rather than following a group conversation (see Chapter 33, this volume).

\subsubsection{Integration and Critique of Behavior Change Interventions}

The control theory framework described here provides a rubric for describing the content and target of existing behavior change interventions. In particular, it reveals that any intervention may be associated with an array of behavior changes, only some of which represent the kind of enduring changes that are desired. Interventions that aim to disturb people's attempt to control what is currently important to them are likely to have short-term benefits if they can effectively block people's actions, but they are likely to have very limited effectiveness in the long term because human control systems are designed to counteract disturbances to meet their goals; people are purposeful and will raise their efforts, sometimes to the extreme of violence, to achieve them. Intervention schemes that utilize threat, withholding of rewards, and restriction of availability would be of this kind. Intervention schemes that provide resources and opportunities (feedback functions) for people to meet their goals and needs have the potential for long-term benefits, partly through helping people meet their goals and partly through making it less likely that people will be drawn into conflict over limited resources.

However, even in a plentiful environment, the most fundamental conflicts (e.g., between being honest vs. kind; being adventurous vs. safe) persist. The most pernicious conflicts are present within the individual and may be outside their immediate awareness. Therefore, the paramount aim is to provide opportunities for people to resolve conflict. Control theory suggests that people require environments in which they feel safe enough to experience uncertainty, error, and risk. Further, they require environments in which they can allow the trialand-error changes observable in their thoughts, feelings, and behavior to persist long enough to identify reorganizations of the control systems driving the conflicting goals that enable them to restore control. Interventions of this kind are harder to pin down but they would include campaigns, groups, and therapies that embrace uncertainty, risk, making mistakes, individuality, creativity, play, freedom of expression, and exploration. The following section introduces interventions informed by control theory that incorporate some of these key elements.

\subsection{Evidence Base for the Use of Control Theory in Changing Behavior}

\subsubsection{Child Development and Parenting}

Possibly one of the most successful sets of resources based on control theory has been the 
Wonder Weeks program (van de Rijt-Plooij \& Plooij, 1993). The Wonder Weeks program, initially published as a book and later launched as a mobile phone app, is aimed at new parents and describes to them the early stages of infant development in a highly accessible way. It explains how the infant's "fussy" periods are transitory; are preceded by, or co-occur with, the emergence of a new type of perception; and are followed by a "mental leap" shown in new skills and abilities. Within control theory terms, each mental leap involves the construction of an input function that extracts an increasingly abstract perceptual signal that can now be controlled via the already developed lower-level systems through feedback control. By helping parents to understand this process in lay terms, the authors aim to help parents work through their baby's challenging developmental stages. Based on control theory, Plooij's research has indicated that each developmental stage represents a new class of perception that the baby is learning to control (van de RijtPlooij \& Plooij, 1993). Skill development in infancy is consistent with our earlier description of reorganization; until the child masters a new skill through trial-and-error reorganization, they can experience the distress of losing control temporarily and show unusual changes in behavior.

Based on the Wonder Weeks program, van de Rijt-Plooij, van der Stelt, and Plooij (1996) developed a Dutch parental support and education program called "Hordenlopen" ("Leaping Hurdles") for a group of single mothers who were at risk of abusing their infants. The course made parents aware of the regression periods, explained that their babies could not help being difficult, and showed them how they could comfort their babies in these difficult periods and facilitate the new type of perception and consequent learning. In an evaluation study, an experimental group receiving the Leaping Hurdles program was compared with a control group following an alternative, current program. In terms of behavior change, the study found that parents in the Leaping
Hurdles program reported more control over their parenting, their infants scored higher on the measures of skill performance, and their children were socially more accepting and open toward strangers. Notably, no research appears to have been conducted on the changes that might occur within parents after the program. One might predict that their reference values for what would constitute a problem with their child might increase following the program, such that the parent is able to manage the child's distress during the period of regression rather than increasing their efforts in a way that overcompensates for the child's distress and exacerbates it.

\subsubsection{Education}

Control theory has informed a variety of interventions within the education system and a number of manuals have been published (Carey, 2012; Ford, 1997; Good, Grumley, \& Roy, 2003). They each advocate a whole-school approach based on perceptual control theory. The Responsible Thinking Process was developed by Ford (1997) as a way to help staff and students address infringements of the school rules in a mutually respectful manner. It uses specific questioning to help students weigh up for themselves the internal conflicts between their own goals and those of the other pupils, teachers, and the school as whole. There are no published evaluations of the program, although a qualitative case study has reported on the features of effective implementation of the approach (Rynberg, 2016). The Connected School (Good et al., 2003) takes a wider perspective to include all of the relationships within the school, and it takes a more direct approach toward explaining the principles of control theory to school administrators and teachers, utilizing role play and experiential methods. It involves three 4-day workshops and 30 hours of supervision. Good (2010) summarizes the reports from schools across Canada and the United States that describe the impact of the program on 
increasing school attendance, reducing discipline incidents, reduced teacher sick leave, and improvements in students' grades. Finally, a wider perspective is taken in Carey's (2012) Control in the Classroom book, illustrating how control theory informs education as well as relationships and discipline. He builds on earlier empirical work showing how staff and students can be locked into counter-control relationships when punitive or coercive methods are attempted by schoolteachers (Carey \& Bourbon, 2006). He also illustrates how any apparently disruptive behavior can be understood as an attempt at control. Teachers can utilize empirical principles to "test the controlled variable" (see Sidebar 9.2), and they can use questioning to help pupils to explore and understand their own goals and goal conflict.

\subsubsection{Mental Health}

Control theory has informed mental health interventions for a number of decades. For a while, it formed the basis of reality therapy (Glasser, 1981) and paved the way for the development of Grawe's $(2004,2007)$ comprehensive integration of psychological therapies. In more recent years, it has formed the basis of an individual psychotherapy known as method of levels (MOL; Carey, 2006) therapy, following the initial, unpublished work of Powers during the 1950s and 1960s. The MOL therapist allows the client to lead the focus of the session and helps the client to shift and sustain their awareness to the source of the conflict that underlies their difficulties (see Chapter 45, this volume). The MOL therapist manages this through simple questioning about

Sidebar 9.2 The behavioral illusion and testing the controlled variable

Since the rise of behaviorism during the early twentieth century, experimental psychology became the study of the prediction and control of behavior (Mansell \& Carey, 2008). Despite the "cognitive revolution" in the 1950s, research designs persist in attempting to manipulate "stimuli" and measure responses in order to infer the nature of the intervening cognitive processes (Marken, 2002). Yet observers can be mistaken in judging the nature of another person's behavior. One series of studies shows that a volunteer can be given a simple instruction (to keep a knot of a rubber band over a dot on a page while holding a pen) and yet over 90 percent of observers of this activity fail to correctly identify that this was the volunteer's instruction (Willett et al., 2017). This behavioral illusion occurs because observers notice the eyecatching features of a behavior, in this case drawing a shape on the page, and assume that what they have observed was intended or controlled. Yet, according to Powers, and evident in replicated studies, what is controlled is the perception of an aspect of the self or environment. Powers concludes that the science of behavior should therefore require a test for the controlled variable (TCV).

The TCV uses the deductive scientific method. The researcher hypothesizes what aspect of the self or environment the participant is controlling. Next, they apply a variety of disturbances to this putative variable and, if the variable is not controlled by the participant, it should change accordingly. If the variable is, however, kept protected from these disturbances, then it is the controlled variable. The TCV is essentially a way to infer a person's goals, or intentions, to "mind read" without requiring self-report (Marken, 1982). 
present-moment experience, either to help the client describe the problem (Goal One) or to notice disruptions that may indicate "background thoughts" about the problem (Goal Two). Background thoughts may include verbal thoughts, images, feelings, and memories and they allow the client to go "up a level" to their more fundamental goals.

Ideally, clients control their own access to MOL, so that they get it when they want it, as frequently as they want it, for as many sessions as they want. Thus, the principle of control runs through both the delivery and the practice of MOL. To be specific, the therapist's questions act as feedback functions for the client, facilitating the client's goal of trying to put into words, explore, and ultimately resolve a problem. This can often involve helping the client keep difficult experiences in their awareness - i.e., perceptual signals that are far from their desired reference value - because this aids reorganization to resolve goal conflict. When the therapist asks about disruptions, this aids the expression of the client's higher-level goals that are at the edge of awareness. By bringing these to the forefront of awareness, they can be explored; and again this permits reorganization of the conflict that they may be creating. Within Figure 9.2, the client may begin with their awareness at the level of "experiencing the effects of smoking/nicotine" and during MOL become aware that this serves to "reduce stress" which, in turn, at a higher level, serves to "stay healthy." It is only from this perspective that the conflict is clear - the paradox of carrying out an unhealthy activity to stay healthy. An MOL therapist would help a client to get to this realization, stay there, and explore it on their own terms. Appendix 9.2 provides more details on how to carry out MOL therapy.

Most studies on MOL therapy have involved pragmatic samples of patients with wide-ranging mental health problems and they have shown large pre-post effect sizes on measures of distress (Carey \& Mullan, 2008; Carey et al., 2009;
Cocklin et al., 2017). One study within a secondary care mental health service showed larger effect sizes than benchmarked studies and a greater efficiency ratio - the reduction in distress per session (Carey, Tai, \& Stiles, 2013). No randomized trials of MOL therapy have been published but two other mental health interventions based on control theory have been evaluated. One of these, MYLO (Manage Your Life Online), is a computerized agent who engages in a text-based conversation with the user about a current problem (see Chapter 29, this volume). Two studies of students have shown reductions in distress about a problem relative to a comparison computer agent (ELIZA) but no differences in the reduction of anxiety and depression (Bird et al., 2018; Gaffney et al., 2014). The second intervention is a six-session program known as the Take Control Course (TCC), which provides experiential learning on the principles of control theory to primary care mental health patients with a variety of diagnoses (Morris, Mansell, \& McEvoy, 2016). The TCC has been shown to be noninferior at six months follow-up compared to the "low intensity" individual therapy that is typically offered in primary care (Morris et al., 2019). Currently, the TCC is being evaluated in high schools for adolescents with diverse mental health problems.

Taken together, mental health interventions derived from control theory show clear promise, and they are being practiced widely. In addition, the computerized exposure paradigm mentioned in Section 9.2 found specific effects on behavior (Oliver \& Mansell, 2018). Spider-fearful participants were exposed to moving images of spiders in a "virtual corridor" (Healey, Mansell, \& Tai, 2017). They were randomly allocated to one of two yoked conditions - a high control condition in which they could control their perceived distance from the spider image on the screen and a low control condition who received the distances from a yoked high control participant but had very little control. The high control group approached closer to a real spider in a tank after 
the task and they reported avoiding spiders less than the low control group two weeks later.

\subsubsection{Organizations}

Research applying control theory in the field of organizational psychology has focused on building and testing computer models of psychological processes within organizations and work environments (e.g., Vancouver \& Purl, 2017). However, authors have developed control theory interventions for marketing and businesses (Forssell, 2008; Madden, 2014; Twijnstra \& Plooij, 2011). The fundamental contribution of control theory to organizations is the realization that it is not productive to instruct other people's behavior or coerce people into behaving in a particular way. Using control theory, teamwork and leadership are more effectively managed by talking openly about the organization's goals and soliciting feedback from all members on their view of these goals, their ability to contribute to them, and any conflicting goals that may get in the way. Members are given their own responsibility to do things that contribute to achieving and maintaining the organization's goals. Control theory ideas can also be used by individuals to help professional development in a way that is genuinely transformative (Twijnstra \& Plooij, 2011).

A number of studies have tested and confirmed the validity of the control theory model of the hierarchical organization of goals (e.g., Paulssen \& Bagozzi, 2006; Pieters, Baumgartner, \& Allen, 1995). Soldani (1989) reported a study of a control theory teamwork program within a manufacturing group that was struggling to meet production schedules. The intervention was based on the assumption, described in Section 9.3.3, that conflict undermines control and effective performance. In turn, control is reestablished, by all parties, when given the opportunity through open dialogue to sustain awareness on the sources of conflict and allow reorganization within the individuals involved. The interventions involved agreeing on a focal goal for the organization - to meet 95 percent of the production schedule on time from a baseline level of 23 percent. The intervention required meetings between all individuals whose direct or indirect work might support the goal, and opinions and feedback were sought regularly from all members. Each member had a one-to-one meeting with a facilitator (acting as a feedback function) to discuss and raise awareness of any obstacles (disturbances) to the goal. In particular, this provided the opportunity to identify when different people's goals in the organization were not aligned. For example, one manager admitted that she was trying to control her reputation, and she tried to achieve this by scolding employees who she perceived to be challenging it, which entailed that many of the employees controlled for avoiding being criticized, making team meetings conflicted and unproductive. The facilitator was able to use simple questioning to each member to help them reflect on their goals and reprioritize them, given the negative impacts they were having on one another. Each member was given the choice of whether they wanted to pursue the organizational goal or give up their place for another member. Soldani (1989) reported that the group met its goal after the program with no loss of quality or increase on overtime.

\subsection{Future Research and Interventions}

Thus far, the existing evidence for control theory interventions across a wide range of domains has been summarized. However, there is emerging research and practice within a much wider arena of behavior change. This includes patient-perspective health care (Carey, 2017), skills training (Brown-Ojeda \& Mansell, 2018), medication prescribing behaviors (Ferguson, Keyworth, \& Tully, 2018), and dementia (McEvoy et al., 2016). The breadth of applications underlies a fundamental feature of control theory - it is a 
theory that specifies the same principles for all realms of behavior, across societies and culture. It illustrates the generalizability and universality of its principles to human behavior across populations, contexts, and behaviors. Dividing people up into groups based on their roles ignores the fact that individual behaviors involve the same control processes; and what is involved in a person's behavior, and what they learn from that process, in one domain, can apply to another. Based on current theory and research on control theory, an important translational message for policymakers and funders is that investing in generalized approaches to behavior change based on control theory would be vastly more efficient than funding projects for specific "groups." One related advantage of the unifying focus of control theory is that it can bring together diverse theories under a "common language" (Marken \& Mansell, 2013). Examples include the integration of various theories of addiction using control theory (Webb et al., 2010); the integration of self-determination theory (see Chapter 8, this volume) with theories of goal conflict, ambivalence, and self-discrepancy (Kelly et al., 2015); and the analysis of cognitive and behavioral techniques and implementation intentions (see Chapter 39, this volume) acting at different levels of a control hierarchy (Mansell, 2012).

\subsection{Summary and Conclusion}

Powers's control theory provides a unique perspective on behavior change. It assumes, unlike other theories, that behavior is the means to control perceptual input. It also provides an architecture of components that can be used to model people's behavior and its validity can be established through the fit of the model to the behavioral data. It implies a number of different routes to behavior change, each varying in their likely success and longevity. In particular, it points to the detrimental role of conflict between and within individuals and the benefits of ways to help people bring conflicts to awareness and explore them in a way that promotes spontaneous solutions - through a process known as reorganization. The breadth of its application is evident, but clearly further empirical work is necessary to evaluate its enduring benefits and compare them with interventions derived from other established theories of behavior change.

\section{References}

Ashby, W. R. (1952). Design for a Brain. New York: Wiley.

Bird, T., Mansell, W., Wright, J., Gaffney, H., \& Tai, S. (2018). Manage Your Life Online: A web-based randomized controlled trial evaluating the effectiveness of a problem-solving intervention in a student sample. Behavioural and Cognitive Psychotherapy, 46, 570-582. https://doi .org10.1017/S1352465817000820

Bourbon, W. T., \& Powers, W. T. (1999). Models and their worlds. International Journal of Human-

Computer Studies, 50, 445-461. https://doi.org/ 10.1006/ijhc.1998.0263

Brown-Ojeda, C., \& Mansell, W. (2018). Do perceptual instructions lead to enhanced performance relative to behavioral instructions? Journal of Motor Behavior, 50, 312-320.

Carey, T. A. (2006). The Method of Levels: How to Do Psychotherapy Without Getting in the Way. Hayward, CA: Living Control Systems Publishing.

Carey, T. A. (2008). Conflict, as the Achilles heel of perceptual control, offers a unifying approach to the formulation of psychological problems. Counselling Psychology Review, 23, 5-16.

Carey, T. A. (2012). Control in the Classroom: An Adventure in Learning and Achievement. Hayward, CA: Living Control Systems Publishing.

Carey, T. A. (2017). Patient-Perspective Care: A New Paradigm for Health Systems and Services. London: Routledge.

Carey, T. A., \& Bourbon, W. T. (2006). Is countercontrol the key to understanding chronic 
behavior problems? Intervention in School and Clinic, 42, 5-13. https://doi.org/10.1177/ 10534512060420010201

Carey, T. A., Carey, M., Mullan, R. J., Spratt, C. G., \& Spratt, M. B. (2009). Assessing the statistical and personal significance of the method of levels. Behavioural and Cognitive Psychotherapy, 37, 311-324. https://doi.org/10.1017/ S1352465809005232

Carey, T. A., \& Mullan, R. J. (2008). Evaluating the method of levels. Counselling Psychology Quarterly, 21, 247-256. https://doi.org/10.1080/ 09515070802396012

Carey, T.A., Tai, S.J. \& Stiles, W.M. (2013). Effective and efficient: Using patient-led appointment scheduling in routine mental health practice in remote Australia. Professional Psychology: Research and Practice, 44, 405-414. https://doi .org10.1037/a0035038

Carver, C. S., \& Scheier, M. F. (1982). Control theory: A useful conceptual framework for personalitysocial, clinical, and health psychology. Psychological Bulletin, 92, 111-135. https://doi .org/10.1037/0033-2909.92.1.111

Cocklin, A. A., Mansell, W., Emsley, R. et al. (2017). Client perceptions of helpfulness in therapy: A novel video-rating methodology for examining process variables at brief intervals during a single session. Behavioural and Cognitive Psychotherapy, 45, 647-660. https://doi .org 10.1017/S1352465817000273

Ferguson, J., Keyworth, C., \& Tully, M. P. (2018). "If no-one stops me, I'll make the mistake again": Changing prescribing behaviors through feedback; A Perceptual Control Theory perspective. Research in Social and Administrative Pharmacy, 14, 241-247. https:// doi.org/10.1016/j.sapharm.2017.03.001

Ford, E. E. (1997). Discipline for Home and School. Scottsdale, AZ: Brandt Publications.

Forssell, D. (2008). Management and Leadership: Insight for Effective Practice. Hayward, CA: Living Control Systems Publications.

Gaffney, H., Mansell, W., Edwards, R., \& Wright, J. (2014). Manage Your Life Online (MYLO): A pilot trial of a conversational computer-based intervention for problem solving in a student sample. Behavioural and Cognitive

Psychotherapy, 42, 731-746. https://doi

.org10.1017/S135246581300060X

Glasser, W. (1981). Stations of the Mind: New

Directions for Reality Therapy. New York, USA: Harper Collins.

Good, F. (2010). A Connected School: Improving Schools and Communities from the Inside Out. www.pctweb.org/Connected.pdf

Good, E. P., Grumley, J., \& Roy, S. (2003). A Connected School. Chapel Hill, NC: New View Publications.

Grawe, K. (2004). Psychological Therapy. Cambridge, MA: Hogrefe Publishing.

Grawe, K. (2007). Neuropsychotherapy: How the Neurosciences Inform Effective Psychotherapy.

Mahwah, NJ: Lawrence Erlbaum Associates.

Halper, L. R., Vancouver, J. B., \& Bayes, K. A. (2018). Self-efficacy does not appear to mediate training's effect on performance based on the moderationof-process design. Human Performance, 31, 216237. https://doi.org/10.1080/ 08959285.2018.1509343

Healey, A., Mansell, W., \& Tai, S. (2017). An experimental test of the role of control in spider fear. Journal of Anxiety Disorders, 49, 12-20. http://dx.doi.org/10.1016/j.janxdis.2017.03.005

Kelly, R. E., Mansell, W., \& Wood, A. M. (2015). Goal conflict and well-being: A review and hierarchical model of goal conflict, ambivalence, selfdiscrepancy and self-concordance. Personality and Individual Differences, 85, 212-229. https:// doi.org/10.1016/j.paid.2015.05.011

Madden, B. J. (2014). Reconstructing Your Worldview. Naperville, IL: LearningWhatWorks.

Mansell, W. (2012). The transdiagnostic approach: The importance of formulating interpersonal and intrapersonal control. In W. Dryden (Ed.), Cognitive Behavioural Therapies (pp. 261-283). London: SAGE.

Mansell, W., \& Huddy, V. (2018). The assessment and modeling of perceptual control: A transformation in research methodology to address the replication crisis. Review of General Psychology, 22, 305320. https://doi.org/10.1037/gpr0000147

Marken, R. (1982). Intentional and accidental behavior: A control theory analysis. Psychological Reports, 
50, 647-650. https://doi.org/10.2466/ pr0.1982.50.2.647

Marken, R. (2002). Looking at behavior through control theory glasses. Review of General Psychology, 6, 260-270.

Marken, R. S. (2013). Taking purpose into account in experimental psychology: Testing for controlled variables. Psychological Reports, 112, 184-201. https://doi.org/10.2466/03.49.PR0.112.1.184201

Marken, R. S., \& Mansell, W. (2013). Perceptual control as a unifying concept in psychology. Review of General Psychology, 17, 190-195. HTTPS://DOI.ORG10.1037/a0032933

McClelland, K. (2004). The collective control of perceptions: Constructing order from conflict. International Journal of Human-Computer Studies, 60, 65-99. https://doi.org/10.1016/ j.ijhcs.2003.08.003

McEvoy, P., Eden, J., Morris, L., \& Mansell, W. (2016). Dementia: Towards a perceptual control theory perspective. Quality in Ageing and Older Adults, 17, 229-238. https://doi.org/10.1108/QAOA-032015-0013

Morris, L., Lovell, K., McEvoy, P. et al. (2019). A brief transdiagnostic group (the Take Control Course) compared to individual low-intensity CBT for depression and anxiety: a randomized noninferiority trial. Unpublished manuscript, University of Manchester.

Morris, L., Mansell, W., \& McEvoy, P. (2016). The Take Control Course: Conceptual rationale for the development of a transdiagnostic group for common mental health problems. Frontiers in Psychology, 7, 99. https://doi.org/10.3389/ fpsyg.2016.00099

Oliver, K., \& Mansell, W. (2018). What is avoidance and when is it a problem? A control theory approach to approach-avoidance conflict in spider fears using a force-feedback joystick paradigm. Unpublished manuscript, University of Manchester. https://doi.org/10.13140/ RG.2.2.19390.38724

Paulssen, M., \& Bagozzi, R. P. (2006). Goal hierarchies as antecedents of market structure. Psychology and Marketing, 23, 689-709. https://doi.org/ 10.1002/mar.20124
Pieters, R., Baumgartner, H., \& Allen, D. (1995). A means-end chain approach to consumer goal structures. International Journal of Research in Marketing, 12, 227-244. https://doi.org/10.1016/ 0167-8116(95)00023-U

Powers, W. T. (1973/2005). Behavior: The Control of Perception. New York: Hawthorne.

Powers, W. T. (1978). Quantitative analysis of purposive systems: Some spadework at the foundations of scientific psychology. Psychological Review, 85, 417-435. http://dx.doi .org/10.1037/0033-295X.85.5.417

Powers, W. T. (1992). Living Control Systems II: Selected Papers of William T. Powers. Gravel Switch, KY: The Control Systems Group.

Powers, W. T. (2008). Living Control Systems III: The Fact of Control. New York: Benchmark Publications.

Powers, W. T., Clark, R. K., \& McFarland, R. L. (1960). A general feedback theory of human behavior: Part I. Perceptual and Motor Skills, 11, 71-88.

Rabinovich, Z., \& Jennings, N. R. (2010). A hybrid controller based on the egocentric perceptual principle. Robotics and Autonomous Systems, 58, 1039-1048. https://doi.org/10.1016/j .robot.2010.05.002

Robertson, R. J., \& Glines, L. A. (1985). The phantom plateau returns. Perceptual and Motor Skills, 61, 55-64. https://doi.org/10.2466/pms.1985.61.1.55

Rynberg, A. D. (2016). Using RTP (responsible thinking process) as a lever for improving school culture: A case study of an alternative secondary school's implementation of RTP. Unpublished $\mathrm{PhD}$ dissertation, Western Michigan University.

Sadurní, M., Burriel, M. P., \& Plooij, F. X. (2010). The temporal relation between regression and transition periods in early infancy. The Spanish Journal of Psychology, 13, 112-126. https://doi .org/10.1017/S1138741600003711

Soldani, J. (1989). Effective personnel management: An application of perceptual control theory. Advances in Psychology, 62, 515-529. http:// ww.livingcontrolsystems.com/intro_papers/per sonnel_mgmt.pdf

Thaler, R. H., \& Sunstein, C. R. (2008). Nudge: Improving Decisions about Health, Wealth, and Happiness. New Haven, CT: Yale University Press. 
Twijnstra, M. H., \& Plooij, F. X. (2011). Oei, ik groei! voor managers [Oops, I'm Growing! for Managers]. Utrecht: Kosmos Uitgevers.

Vancouver, J. B. (2005). The depth of history and explanation as benefit and bane for psychological control theories. Journal of Applied Psychology, 90, 38-52. https://doi.org/10.1037/00219010.90.1.38

Vancouver, J. B., Gullekson, N. L., Morse, B. J., \& Warren, M. A. (2014). Finding a between-person negative effect of self-efficacy on performance: Not just a within-person effect anymore. Human Performance, 27, 243-261. https://doi.org/ $10.1080 / 08959285.2014 .913593$

Vancouver, J. B., \& Purl, J. D. (2017). A computational model of self-efficacy's various effects on performance: Moving the debate forward. Journal of Applied Psychology, 102, 599-616. http://dx .doi.org/10.1037/ap10000177

Vancouver, J. B., \& Scherbaum, C. A. (2008). Do we self-regulate actions or perceptions? A test of two computational models. Computational and Mathematical Organization Theory, 14, 1-22. https://doi.org10.1007/s10588-008-9021-7

van de Rijt-Plooij, H., \& Plooij, F. X. (1993). Distinct periods of mother-infant conflict in normal development: Sources of progress and germs of pathology. Journal of Child Psychology and

Psychiatry, 34, 229-245. https://doi.org/10.1111/ j.1469-7610.1993.tb00981.x

van de Rijt-Plooij, H., van der Stelt, J. \& Plooij, F. (1996). Hordenlopen: Een preventieve oudercursus voor de eerste anderhalf jaar [Hurdling: A Preventive Parent Course for the First Year and a Half]. Lisse: Swets \& Zeitlinger.

Webb, T. L., Sniehotta, F. F., \& Michie, S. (2010). Using theories of behaviour change to inform interventions for addictive behaviours. Addiction, 105, 1879-1892. https://doi.org/10.1111/j.13600443.2010.03028.x

Wiener, N. (1948). Cybernetics and Control and Communication in the Animal and the Machine. Cambridge, MA: Technology Press.

Willett, A., Marken, R. S., Parker, M., \& Mansell, W. (2017). Control blindness: Why people can make incorrect inferences about the intentions of others. Attention, Perception, and Psychophysics, 79, 841-849. https://doi.org/10.3758/s13414-0161268-3

Young, R. (2017). A general architecture for robotics systems: A perception-based approach to artificial life. Artificial Life, 23, 236-286. 